\title{
Endoscopic Closure of an Acute Duodenal Perforation Occurring during Endoscopic Ultrasound Using Endoclips and Polyglycolic Acid Sheets with Fibrin Glue
}

\author{
Mana Matsuoka Katsumasa Kobayashi Yukito Okura \\ Tomohiro Mochida Takahito Nozaka Ayako Sato Masato Yauchi \\ Taichi Matsumoto Yohei Furumoto Takao Horiuchi Toru Asano \\ Department of Gastroenterology, Tokyo Metropolitan Bokutoh Hospital, Tokyo, Japan
}

\section{Keywords}

Duodenal perforation · Endoscopic closure · Polyglycolic acid sheets · Fibrin glue · Case report

\begin{abstract}
Acute duodenal perforation during endoscopic ultrasound (EUS) is a serious complication. The conventional endoscopic treatment for duodenal perforations such as endoscopic clipping is unsatisfactory; recently, the effectiveness of over-the-scope clipping (OTSC) has been reported. A 91-year-old woman was referred to our hospital with the chief complaint of jaundice. Contrast-enhanced computed tomography showed a $2-\mathrm{cm}$ mass in the pancreatic head; we planned EUS-guided fine-needle aspiration. During exploration for a puncture route from the duodenal bulb using a linear echoendoscope under carbon dioxide insufflation, the duodenal lumen was suddenly filled with blood. A perforation $<15 \mathrm{~mm}$ was identified in the superior duodenal horn. We attempted an endoscopic closure with multiple endoclips but could not completely close the perforation site. Strips of bioabsorbable polyglycolic acid (PGA) sheets were placed over the gaps between the endoclips with biopsy forceps and fixed in place with fibrin glue, completely covering the perforation site. Two days after the procedure, the perforation site had closed. Nine days later, endoscopic biliary stenting was performed. The patient
\end{abstract}

Mana Matsuoka
Department of Gastroenterology, Tokyo Metropolitan Bokutoh Hospital
$4-23-15$, Kotobashi, Sumida-ku
Tokyo 130-8575 (Japan)
manamatsuoka@yahoo.co.jp




\section{Case Reports in Gastroenterology}

Case Rep Gastroenterol 2021;15:253-261 DOI: $10.1159 / 000512474$

(c) 2021 The Author(s). Published by S. Karger AG, Basel www.karger.com/crg

Matsuoka et al.: Clips and Polyglycolic Acid Sheets for Duodenal Closure

was diagnosed with pancreatic cancer through bile cytology, and the optimal supportive care for her age was selected. Endoscopic tissue shielding with PGA sheets and fibrin glue is increasingly being reported for use during gastrointestinal endoscopic procedures. In this case, surgery was avoided due to successful endoscopic treatment using endoclips and PGA sheets with fibrin glue without OTSC. This method may be useful for repairing acute duodenal perforations during EUS and should therefore be known to pancreatobiliary endoscopists.

(c) 2021 The Author(s)

Published by S. Karger AG, Basel

\section{Introduction}

Acute duodenal perforation occurring during endoscopic ultrasound (EUS) or endoscopic retrograde cholangiopancreatography (ERCP) is a serious and potentially life-threatening complication. Patients diagnosed with duodenal perforation may progress to acute peritonitis and septic shock, which is associated with a high mortality rate [1]. In the past, surgery was the mainstay of the treatment for duodenal perforations [2]. The conventional endoscopic treatment for duodenal perforations using endoscopic clipping is not satisfactory because it is usually difficult to completely close a perforation site $>10 \mathrm{~mm}[3,4]$. Recently, the effectiveness of over-the-scope clipping (OTSC) for duodenal perforations associated with pancreatobiliary endoscopic procedures has been reported [5, 6].

Within the literature evaluating gastrointestinal procedures, some reports detailing favorable therapeutic results have been published for the prevention of delayed perforation and repair of perforated ulcers after endoscopic submucosal dissection (ESD) using polyglycolic acid (PGA) sheets with fibrin glue [7-10]. However, there are no reports on endoscopic repair using PGA sheets with fibrin glue for duodenal perforations associated with pancreatobiliary endoscopy such as EUS and ERCP. As a result, this method is unfamiliar to pancreatobiliary endoscopists. As postoperative perforations are usually large and often fragile, an additional open surgery is currently the only method available to treat large and delayed postoperative perforations, and thus there is an urgent need for an endoscopic technique for the repair of such perforations. Endoscopic closure using PGA sheets with fibrin glue may be useful as it negates the need for repair surgery for perforations associated with pancreatobiliary endoscopic procedures and is a therapeutic approach that should be known to pancreatobiliary endoscopists. We report a case of acute duodenal perforation occurring during EUS in a 91year-old woman that was successfully treated using endoclips and PGA sheets with fibrin glue.

\section{Case Report}

A 91-year-old woman was referred to our hospital with the chief complaint of jaundice after experiencing it for 3 days. Her medical history consisted of decades of high blood pressure, treated with an antihypertensive drug. She also had been diagnosed with gallstones and thus had been administered conservative treatment without any recurring symptoms for decades. Her serum total bilirubin level was $4.9 \mathrm{mg} / \mathrm{dL}(83.79 \mu \mathrm{mol} / \mathrm{L}$; normal range $0.4-$ $1.5 \mathrm{mg} / \mathrm{dL}$ ). An enhanced computed tomography scan revealed a $20-\mathrm{mm}$ mass lesion in the head of the pancreas with a contrast effect that was poorer than that of the surrounding pancreatic parenchyma, resulting in the obstructive jaundice (Fig. 1). We planned to implement

\section{Karger'=}




\section{Case Reports in Gastroenterology}

Case Rep Gastroenterol 2021;15:253-261

DOI: $10.1159 / 000512474$

(c) 2021 The Author(s). Published by S. Karger AG, Basel www.karger.com/crg

Matsuoka et al.: Clips and Polyglycolic Acid Sheets for Duodenal Closure

an EUS-guided fine-needle aspiration procedure to extract tissue from the pancreatic mass. The purpose of this was to determine and confirm a diagnosis of pancreatic cancer via histopathology. During the exploration for a puncture route from the duodenal bulb using a linear echoendoscope (GF-UCT260; Olympus, Tokyo, Japan) under carbon dioxide insufflation, the duodenal lumen was suddenly filled with blood. A perforation with a diameter of $<15 \mathrm{~mm}$ was identified in the superior duodenal horn (Fig. 2a). We attempted an endoscopic closure with multiple endoclips (Quick Clip Pro, HX-610-090L; Olympus), while a distal attachment (D-201-11804; Olympus) was placed at the tip of the endoscope (GIF-Q260J; Olympus). As the event was unanticipated, there were no preparations in place for an OTSC procedure. However, the procedure was difficult due to space constraints and poor operability of the lesion, and thus the perforation site could not be closed completely (Fig. 2b). The following procedure was performed in accordance with previously described methodology $[8,10]$ : A 0.15-mmthick PGA sheet (Neoveil; Gunze Co., Kyoto, Japan) was cut into $15 \times 5 \mathrm{~mm}$-sized pieces. Four strips of these sheets were made, which were placed over the gaps between the endoclips with biopsy forceps (radial Jaw4P; Boston Scientific, Marlborough, MA, USA). Fibrin glue (Beriplast P Combi-Set; CSL Behring Pharma, Tokyo, Japan) was applied using a spray tube tailored for endoscopy. We advanced the spray tube into the PGA sheet-filled region so that solution A (fibrinogen) was inserted between the sheets. Next, solution B (thrombin) was injected deeper inside the PGA sheet-filled region using another spray tube to form fibrin gel (Fig. 2c). The perforation site was completely covered, with no extraintestinal leakage of the contrast medium (Fig. 3). The procedure time was $52 \mathrm{~min}$. There were almost no intraoperative bleeding or adverse events. Postprocedural computed tomography showed free air on the surface of the liver but no leakage of the contrast medium from the intestine. Thereafter, antibiotics ( $1 \mathrm{~g}$ of meropenem administered every $8 \mathrm{~h}$ for 10 days) and proton pump inhibitors were administered intravenously, and a nasogastric tube was inserted for decompression. Two days after the procedure, the PGA sheets had already fallen away (Fig. 2d), with no visible signs of the perforation site remaining and no leakage of the contrast medium detected. Due to this, we concluded that the perforation site had closed. The clinical course after the procedure was uneventful, with only a mild fever experienced for 2 days. Endoscopic biliary stenting for obstructive jaundice was performed 9 days later. The patient was diagnosed with pancreatic cancer through bile cytology, and the optimal supportive care for her age was selected. She was discharged from the hospital 26 days after the procedure.

\section{Discussion and Conclusion}

We report a case of acute duodenal perforation occurring during EUS which was successfully treated using endoclips and PGA sheets with fibrin glue. An endoscopic closure using PGA sheets with fibrin glue may be effective for the repair of acute duodenal perforations occurring during pancreatobiliary endoscopic procedures such as EUS and ERCP. Therefore, it is important for pancreatobiliary endoscopists to be fully conversant with this treatment modality.

The incidence of gastrointestinal perforations is reported to be $0.3-1.0 \%$ for ERCP and $0.09 \%$ for EUS-guided fine-needle aspiration [11]. Although the incidence of gastrointestinal perforations during pancreatobiliary endoscopy is low, there is a high risk of developing serious complications that can be potentially life-threatening, and prompt and reliable treatment is therefore necessary [2]. Perforations of the lateral or medial wall of the duodenum caused by the device itself are usually large and carry a high mortality rate [12]. If the perforation is

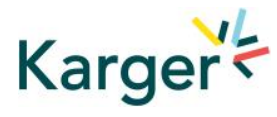




\section{Case Reports in Gastroenterology}

Case Rep Gastroenterol 2021;15:253-261

DOI: $10.1159 / 000512474$

(c) 2021 The Author(s). Published by S. Karger AG, Basel www.karger.com/crg

Matsuoka et al.: Clips and Polyglycolic Acid Sheets for Duodenal Closure

immediately recognized, an endoscopic closure should be attempted [12]. However, if endoscopic treatment is unsuccessful, immediate surgery is usually required [12]. Although surgery allows for a reliable repair, it has the disadvantages of being invasive and having a high risk of complications as well as a high cost [11]. In the present case, surgical intervention may have been unsuccessful and led to a poor prognosis due to the age of the patient and the advanced stage of the pancreatic cancer; therefore, we considered it best to avoid surgery. OTSC is a relatively new technique that has been successfully used to treat gastrointestinal bleeding, perforations, anastomotic leakages, and fistulas. It is also useful for the closure of large defects that existing devices such as endoclips struggle with $[3,6]$. Some reports have described favorable results with OTSC in cases of duodenal perforations occurring during pancreatobiliary endoscopic procedures [1]. Endoscopic closure using OTSC may well become the first line of treatment for acute duodenal perforations occurring during pancreatobiliary endoscopic procedures in the future. However, in the present case, not having anticipated any untoward events, we were unprepared for OTSC and chose the only feasible alternative available.

The endoscopic closure of a duodenal perforation with endoclips alone is often difficult [12], although the additional use of shielding with PGA sheets and fibrin glue may be useful. The use of PGA sheets in combination with fibrin glue has healing effects, as the sheets serve as scaffolds for tissue regeneration [7]. The PGA sheets serve as absorbent organization-reinforcing structures, which are spontaneously absorbed within 4-15 weeks. They have been used as an organization-reinforcing structure in the field of surgery, such as respiratory and oral surgeries, for several years $[13,14]$. Recently, the usefulness of shielding using PGA sheets for perforated ulcers has been reported not only in post-ESD perforations but also in duodenal ulcer perforations within gastrointestinal endoscopy $[8,10,15]$. It is believed that when the perforation area is firmly covered with the PGA sheets, leakage of the digestive juices into the peritoneal and retroperitoneal cavities is prevented, and the perforation can be closed by granulation, with the PGA sheets serving as a base [9]. On the other hand, one of the problems with PGA sheets is that the filling method is difficult, and there is a possibility that they may come off despite trying to steadily adhere them onto the site of the perforation. However, there are some reports suggesting that the use of endoclips to fix the PGA sheets firmly in place to cover the ulcer is effective in preventing them from detaching from the filled area [8]. In the present case, the endoscopic closure of the duodenal perforation with endoclips alone was difficult due to space constraints and the poor operability of the lesion. Thus, filling the gaps between the endoclips using PGA sheets with fibrin glue allowed us to achieve complete closure of the perforation site. The fact that we could complete the surgery and successfully seal the site of the perforation completely using this technique, despite poor visibility and operability, highlights the utility of this technique. This could not have been accomplished using endoclips alone. However, complete closure may not always be possible using PGA sheets with fibrin glue alone, depending on the perforation size and the stability of the PGA sheets. In the present case, the combination of PGA sheets and endoclips was effective.

Through this case, we found that endoscopic closure of acute duodenal perforations occurring during EUS can be safely and effectively managed using endoclips and PGA sheets with fibrin glue. The use of PGA sheets with fibrin glue as an additional modality may prove effective when it is difficult to close the perforation completely with endoclips or OTSC alone in cases of acute duodenal perforations occurring during pancreatobiliary endoscopic procedures.

After duodenal ESD, covering a postoperative ulcer with pieces of a PGA sheet is often difficult because of the gravitational influence in the duodenal lumen. Moreover, early

\section{Karger'=}




\section{Case Reports in Gastroenterology}

\begin{tabular}{l|l}
\hline Case Rep Gastroenterol 2021;15:253-261 \\
\hline DOI: 10.1159/000512474 & $\begin{array}{l}\text { @ 2021 The Author(s). Published by S. Karger AG, Basel } \\
\text { www.karger.com/crg }\end{array}$ \\
\hline
\end{tabular}

Matsuoka et al.: Clips and Polyglycolic Acid Sheets for Duodenal Closure

slippage of the sheets from the postoperative ulcer has been reported [8]. Therefore, it is probably difficult to close the PGA sheet alone for duodenal perforation during pancreatobiliary endoscopic procedures; meanwhile, PGA sheets may be useful as an aid for closure with both endoclips and OTSC. Taken together, surgery may be avoided by the additional use of PGA sheets in unsuccessful cases of perforation closure by endoclips or OTSC. On the other hand, when the operability or the visual field is poor, it is important to consider emergency surgery.

Since duodenal perforation during pancreatobiliary endoscopic procedures is a serious and potentially life-threatening complication, it is important to select the appropriate treatment method for each case. Therefore, this report will help to raise awareness of this method among pancreatobiliary endoscopists. Further studies are required to evaluate the effectiveness of this technique and verify the results presented in this report.

\section{Statement of Ethics}

Written informed consent was obtained from the patient for publication of this case report and any accompanying images. All procedures were performed in accordance with the ethical standards laid down in the 1964 Declaration of Helsinki and its later amendments.

\section{Conflict of Interest Statement}

The authors have no conflicts of interest to declare.

\section{Funding Sources}

None to report.

\section{Author Contributions}

All authors are in agreement with the contents of this paper. M. Matsuoka wrote the manuscript. K. Kobayashi wrote and critically reviewed the manuscript. Y. Okura, T. Mochida, and T. Nozaka served as assistants during the endoscopic procedure. A. Sato, M. Yauchi, and T. Matsumoto provided clinical advice. Y. Furumoto, T. Horiuchi, and T. Asano supervised the production of the manuscript. All authors were involved in the writing of this report and approved the final version.

\section{References}

1 El Bacha H, Prat F. Endoscopic management of iatrogenic EUS-related duodenal perforations with over-thescope clips. Endosc Int Open. 2020 Jan;8(1):E59-63.

2 Lee TH, Han JH, Park SH. Endoscopic treatments of endoscopic retrograde cholangiopancreatographyrelated duodenal perforations. Clin Endosc. 2013 Sep;46(5):522-8.

3 Parodi A, Repici A, Pedroni A, Blanchi S, Conio M. Endoscopic management of GI perforations with a new over-the-scope clip device (with videos). Gastrointest Endosc. 2010 Oct;72(4):881-6.

\section{Karger'=}




\section{Case Reports in Gastroenterology}

4 Haider S, Kahaleh M. The use of endoscopic clipping devices in the treatment of iatrogenic duodenal perforation. Gastroenterol Hepatol (N Y). 2010 Oct;6(10):660-1.

5 Donatelli G, Vergeau BM, Dritsas S, Dumont JL, Tuszynski T, Meduri B. Closure with an over-the-scope clip allows therapeutic ERCP to be safely performed after acute duodenal perforation during diagnostic endoscopic ultrasound. Endoscopy. 2013;45(Suppl 2 UCTN):E392-3.

6 Khater S, Rahmi G, Perrod G, Samaha E, Benosman H, Abbes L, et al. Over-the-scope clip (OTSC) reduces surgery rate in the management of iatrogenic gastrointestinal perforations. Endosc Int Open. 2017 May; 5(5):E389-94.

7 Seehawong U, Morita Y, Nakano Y, Iwasaki T, Krutsri C, Sakaguchi H, et al. Successful treatment of an esophageal perforation that occurred during endoscopic submucosal dissection for esophageal cancer using polyglycolic acid sheets and fibrin glue. Clin J Gastroenterol. 2019 Feb;12(1):29-33.

8 Doyama H, Tominaga K, Yoshida N, Takemura K, Yamada S. Endoscopic tissue shielding with polyglycolic acid sheets, fibrin glue and clips to prevent delayed perforation after duodenal endoscopic resection. Dig Endosc. 2014 Apr;26(Suppl 2):41-5.

9 Takimoto K, Hagiwara A. Filling and shielding for postoperative gastric perforations of endoscopic submucosal dissection using polyglycolic acid sheets and fibrin glue. Endosc Int Open. 2016 Jun;4(6):E6614.

10 Takimoto K, Imai Y, Matsuyama K. Endoscopic tissue shielding method with polyglycolic acid sheets and fibrin glue to prevent delayed perforation after duodenal endoscopic submucosal dissection. Dig Endosc. 2014 Apr;26(Suppl 2):46-9.

11 Liu Y, Wang D, Li Z. Endoscopic closure for EUS and ERCP related duodenal perforation by endoclips. Gastroenterol Res Pract. 2016;2016:1051597.

12 Paspatis GA, Dumonceau JM, Barthet M, Meisner S, Repici A, Saunders BP, et al. Diagnosis and management of iatrogenic endoscopic perforations: European Society of Gastrointestinal Endoscopy (ESGE) Position Statement. Endoscopy. 2014 Aug;46(8):693-711.

13 Kim SW, Kim D. Management of long-term persistent air leakage developed after bullectomy for giant bullous lung disease associated with neurofibromatosis type 1. J Thorac Dis. 2016 Jan;8(1):E140-3.

14 Akashi M, Matsumoto K, Takeda D, Yamashita J, Yatagai N, Hashikawa K, et al. Dental rehabilitation for free fibula flap-reconstructed mandible with scar contracture: a technical note. Dent J (Basel). 2019 Jun;7(3):65.

15 Sasaki F, Kanmura S, Nasu Y, Hashimoto S, Taguchi H, Numata M, et al. Double-balloon enteroscopy-assisted closure of perforated duodenal diverticulum using polyglycolic acid sheets. Endoscopy. 2015;47(Suppl 1 UCTN):E204-5. 
Case Reports in Gastroenterology
Case Rep Gastroenterol 2021;15:253-261

DOI: $10.1159 / 000512474$

(c) 2021 The Author(s). Published by S. Karger AG, Basel www.karger.com/crg

Matsuoka et al.: Clips and Polyglycolic Acid Sheets for Duodenal Closure

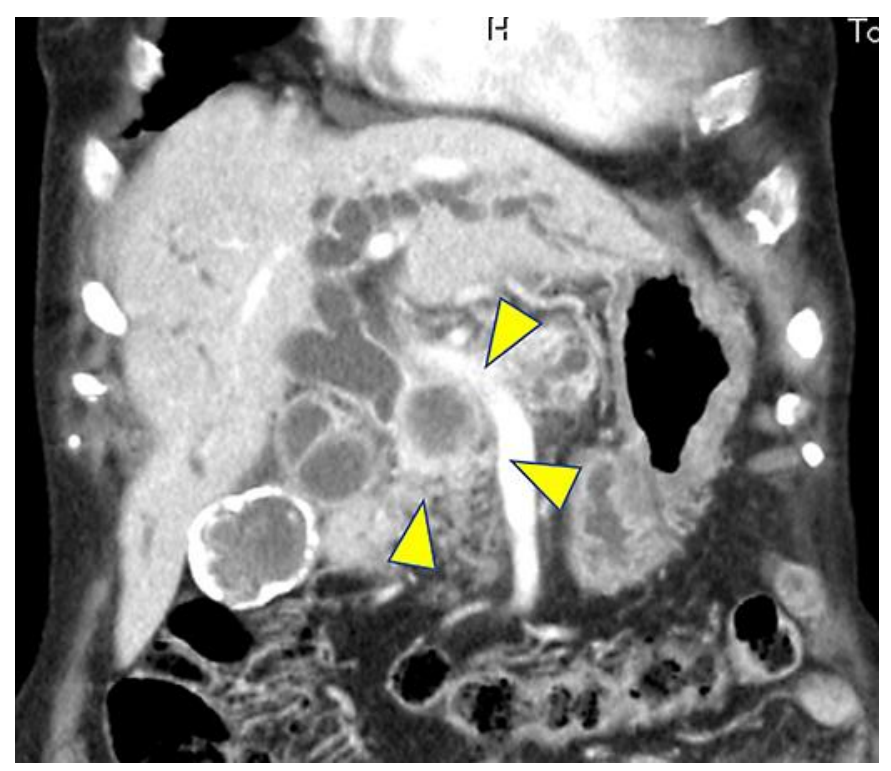

Fig. 1. Enhanced computed tomography scan showing a 20-mm mass lesion in the head of the pancreas with a contrast effect that is poorer than that of the surrounding pancreatic parenchyma (arrowheads). 
Case Reports in Gastroenterology
Case Rep Gastroenterol 2021;15:253-261

DOI: $10.1159 / 000512474$

( 2021 The Author(s). Published by S. Karger AG, Basel www.karger.com/crg

Matsuoka et al.: Clips and Polyglycolic Acid Sheets for Duodenal Closure
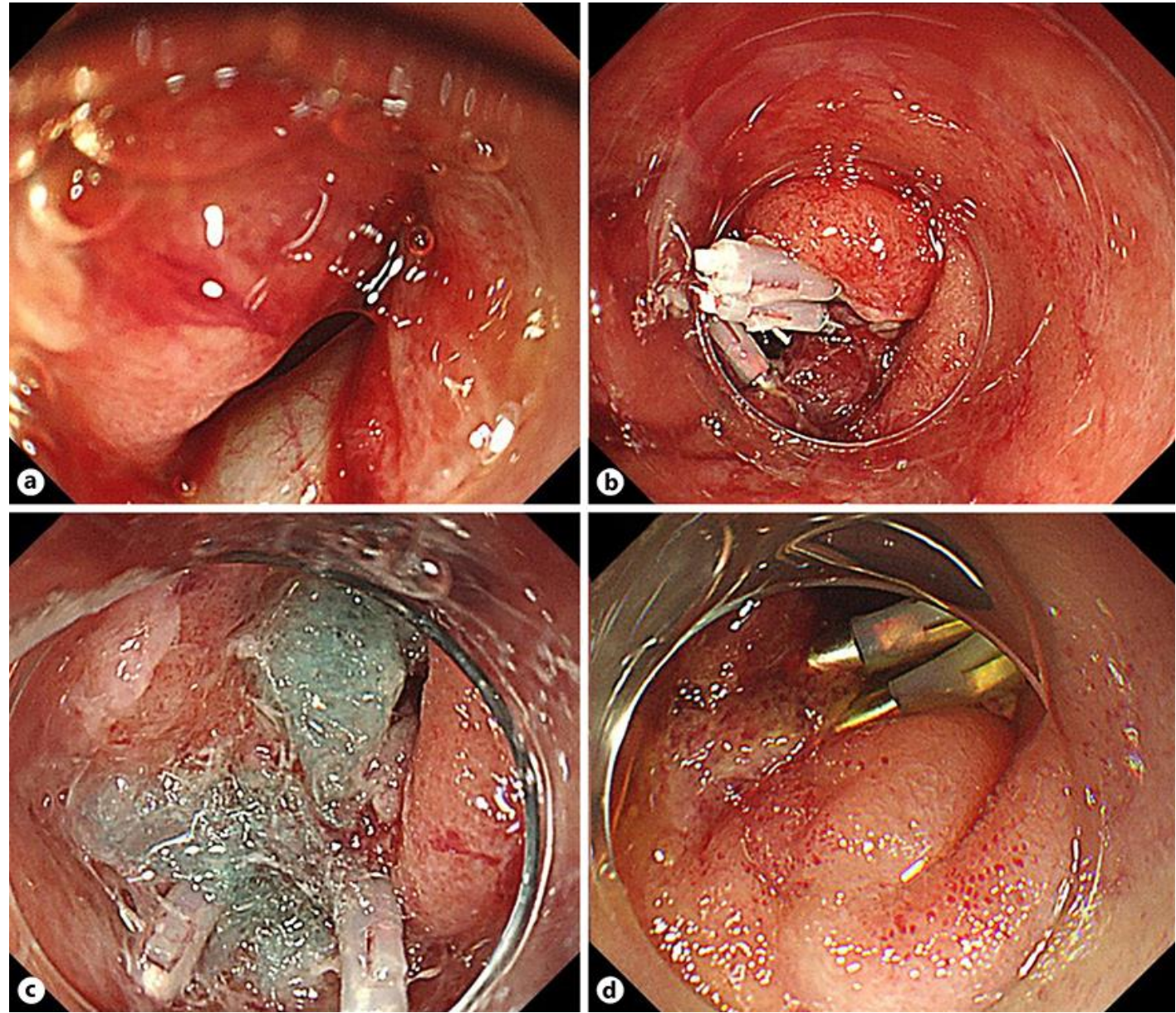

Fig. 2. Endoscopic images. a The perforation site in the superior duodenal horn is $<15 \mathrm{~mm}$ in diameter. b Multiple endoclips are placed to close the perforation site. c The perforation site is completely covered by the polyglycolic acid sheets and fibrin glue. $\mathbf{d}$ The perforation site is closed. 
Case Reports in Gastroenterology
Case Rep Gastroenterol 2021;15:253-261

\begin{tabular}{l|l}
\hline DOI: 10.1159/000512474 & (c) 2021 The Author(s). Published by S. Karger AG, Basel \\
\hline
\end{tabular} www.karger.com/crg

Matsuoka et al.: Clips and Polyglycolic Acid Sheets for Duodenal Closure

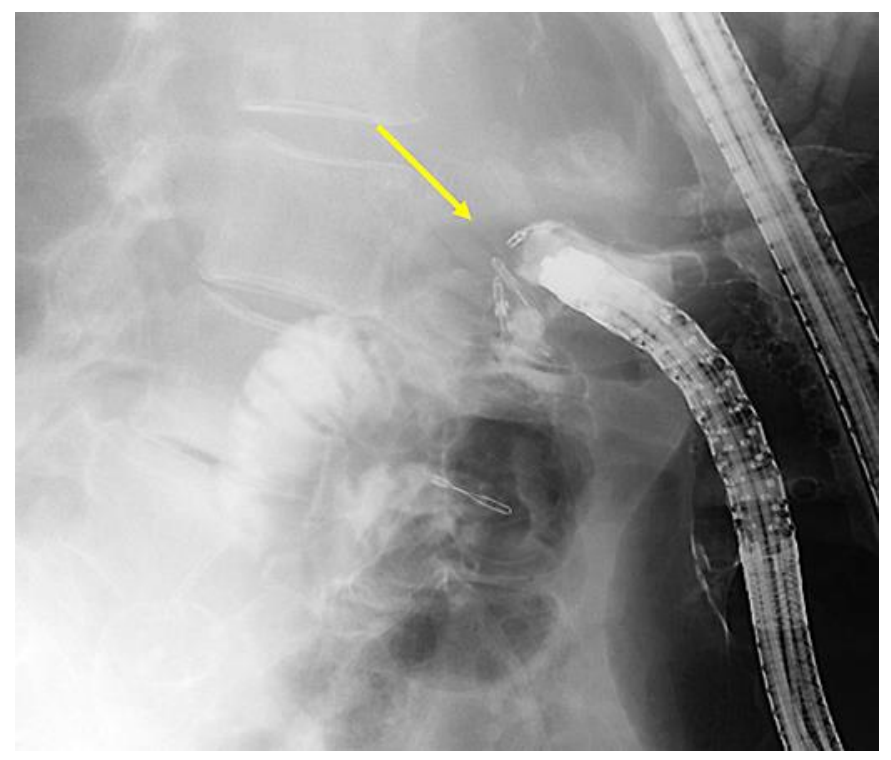

Fig. 3. A gastrointestinal series shows no leakage of the contrast medium from the duodenum; multiple endoclips are observed at the perforation site (arrow). 